\title{
An Introduction to Utopian and Dystopian Post-WTO Regimes and Environments
}

\author{
Junji Nakagawa and Colin B. Picker
}

\section{Contents}

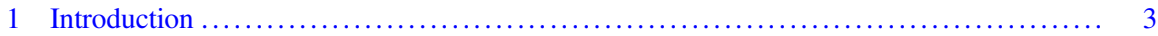

2 Project Conceptual Issues (e.g., Methodological and Theoretical Bases) ............... 6

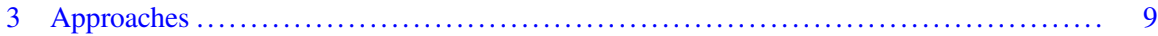

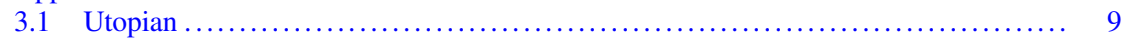

3.1.1 Fundamental Negative Features of the WTO ....................... 9

3.1.2 Identify the Goals or Fundamental Character of the Successor Regime ..... 12

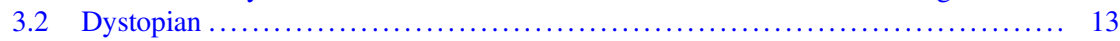

3.2.1 Successful or Positive Aspects of the WTO ........................ 13

3.2.2 Consequences of Not Replacing Those Positives ...................... 14

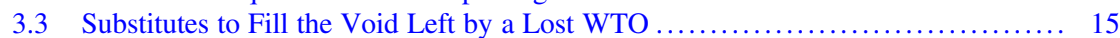

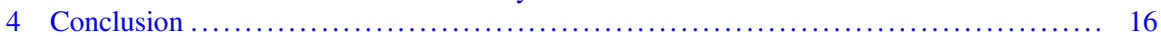

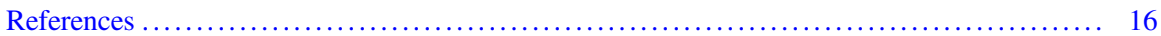

\section{Introduction}

The collection of papers in this book originated from some of the presentations that were made at a series of workshops held around the world in 2019 on the topic of the "Post-WTO". We, along with local hosts at the different workshops, ${ }^{1}$ organised a

Respectively, Professor at the Faculty of Liberal Arts at Chuo Gakuin University; and Executive Dean of the Faculty of Law, Humanities and Arts at the University of Wollongong in Australia.

\footnotetext{
${ }^{1}$ The first workshop was held at the University of Tokyo from the 9th to the 10th January 2019 (thanks to Professor Junji Nakagawa for hosting). The second workshop took place at the Fletcher School, Tufts University on the 26th of July 2019 (thanks to Professor Joel Trachtman for hosting).

J. Nakagawa

Chuo Gakuin University, Abiko, Japan and Anderson, Mori and Tomotsune LLP, Tokyo, Japan e-mail: nakagawa@fla.cgu.ac.jp

C. B. Picker $(\bowtie)$

University of Wollongong, Wollongong, NSW, Australia

e-mail: cpicker@uow.edu.au
} 
series of workshops to explore what might be some of the possibilities or consequences if the WTO collapsed or became largely irrelevant in the international economic arena. As an initial matter, it needs to be stated that this chapter and indeed the entire project, including the other chapters in this collection as well as the presentations and discussions at the workshops held in 2019 and those to be held in the future, are premised on the idea that the project's ultimate goal is to try to help preserve the WTO or what it stands for-a multilateral rule of law regime for international trade. Thus, in no way should the work be viewed as supporting the undermining or denigration of the WTO. It was strongly felt that such serious discussion of a "post-WTO" as were held at the workshops and in the papers would help keep the current regime alive by showing how difficult and challenging might be the international economic legal order (IELO) in a post-WTO world or by showing, in its utopian scenarios, avenues for a future reform of the WTO.

Primarily, the participants were leading scholars in the fields of international economic law. ${ }^{2}$ Government and international organisation officials were for the

The final workshop took place at King's College London from the 18th to the 19th of October 2019 (thanks to Dr. Holger Hestermeyer for hosting). It is expected that future workshops will take place, but they are obviously not reflected in this volume.

${ }^{2}$ The workshop participants (and their presentation titles) included: Pinar Artiran (Post-WTO lessons from EU-Turkey disputes at WTO v EU-Turkey FTA DS mechanisms); Elisa Baroncini (The EU Approach to overcome the WTO DS vacuum: suggesting arbitration on the model of Art. 25 DSU and activating bilateral dispute mechanisms under new EUFTAs); Tomer Broude (Early thoughts on Regulatory Liberalism and the WTO); Leila Choukroune (The Concern with Non-Concerns: Beyond Trade, Power Rights); Kathleen Claussen (Trade's Enforcement Conundrum); Bradly Condon (To Dystopia and Beyond: The WTO in a Warming Megaregional World); Fernando Dias Simoes (Nothing Lasts Forever: The (im)permanence of the AB); Michael Ewing Chow (Between Legislation and Litigation: The WTO as the Missing Middle); David A. Gantz (Post-WTO State-to-State Disputes in FTAs: E.g. USMCA); Henry Gao (Being Digital: The WTO and Data Regulation); Gabriel Gari (A proposal to split the WTO in accordance with the nature of its obligations); Caroline Henckels and Elizabeth Sheargold (Reimagining Public Policy Exceptions in WTO 2.0); Holger Hestermeyer (Trade Dispute settlement without the WTO?); Tomohiko Kobayashi and Yuka Fukunaga (Like a Rolling Stone: Exploring Viable Options for Adjusting the WTO Dispute Settlement Mechanism to the Changing Environment); Qingjan Kong (The Discourse on Fair Trade and its Implication: From Domestic Rules to International Rules); Jurgen Kurtz (Past as Prologue? Historical Parallels and Discontinuities in Modern Trade Wars); Jaemin Lee (What Can We Learn from Our Struggling Nephew?-Recent Discussions on Reform of International Investment Law and Investment Dispute Settlement Proceedings); Simon Lester (The Return of Cordell Hull); Meredith Lewis (From an Omnilateral to Multilateral or Multilateral to Plurilateral Future); Chin Leng Lim (Geneva Still Inspires: The Idea of an Appellate Mechanism for Investment Arbitration); Tsai-yu Lin (Transforming WTO to play a ICSID-like function for FTA disputes in a decentralized trade order); Mitsuo Matsushita (The WTO Shares the Governance of International Trade with FTAs and Other International Organizations); Gregory Messenger (How not to trip over your robes: lessons for a post-WTO dispute settlement system); Andrew Mitchell and Tania Voon (Regulating Cross-Border Data Flows in a Post-WTO World); Junji Nakagawa (A Long and Winding Road toward WTO2.0: Focusing on Its Function as a Forum for Trade Negotiation and Rule-making); James Nedumpara (Rise of Import Substitution Subsidies/Local Content Requirements in Post-WTO Dystopian World); Federico Ortino (Incorporating foreign investment in a future/new WTO); Shin-yi Peng (A New Trade Regime for the Servitization of 
most part not invited as the project sought to ensure that its findings and conclusions might not be viewed as tainted by state or organisational self-interests - even given that such presenters typically would note and believe that their presentations only reflected their own personal views and not those of their employers. It was also felt that such a hard subject, one that government officials cannot even begin to voice for fear it would hasten the end of the WTO, was one particularly suited to and indeed one that is the duty of academics to raise and discuss when others cannot do so.

Due to the different locations of the workshops, regional perspectives were explicitly and implicitly reflected in the explorations, though there is a need for further and deeper opportunities for perspectives from developing countries which may have been less well represented due to the lack of funding to support their participation at the workshops. ${ }^{3}$

The workshop participants were instructed that the workshops (and consequently this collection of some of the papers) were to presuppose (whether correct or not) that the WTO either:

a) Stagnates into the foreseeable future (Doha withers, no new Rounds, at best a few minor amendments, and little new jurisprudence (due to the effective collapse of the DSB)) or

b) Falls apart completely.

While all participants uniformly believed that neither of those possibilities would be desirable, it was generally conceded that neither is inconceivable. After all, the historic sudden collapse of the Soviet Union and the end of the Cold War tells us that anything is possible (in 1986 no one foresaw the end of the Cold War-a much bigger event than simply the demise of the WTO and the current IELO). Similarly, just a year or two before the COVID-19 pandemic, Brexit or the election of Trump

Manufacturing); Colin Picker (Conceiving Utopian and Dystopian Post-WTO Regimes and Environments: Methods, Theories, and Approaches); Rostam J. Neuwirth (GAIA 2048-A 'Glocal Agency in Anthropocene': Cognitive and Institutional Change as 'Legal Science Fiction'); Sonia Elise Roland and David Trubek (A Development Driven Post WTO World); Engela Schlemmer (The demise of multilateralism and the rise of sovereignty); Fiona Smith (Dystopian Food Trade: A Future Without the WTO); Peter-Tobias Stoll (Saving world economic order bottom-up: a network of RTAs/PTAs); Akihiko Tamura (How to Re-construct the Global Trade Order-Awaking a Normativity-aspiring Part of the Soul of the Global Citizens in the Time of Identity Politics and Sustainability); Lisa Toohey (A human centered system of International Economic Law-could we design a self-executing WTO 2.0 that was human focused?); Joel Trachtman (Addressing the WTO's Legislative Capacity Gap); Elizabeth Trujillo (Retaining Normative Impact Post-WTO through Fragmentation); Markus Wagner (The Re-Multilateralization of International Trade Law? Prospects for a post-WTO Era); Heng Wang (The Int'l Governance Crisis and Post-WTO: A ChinaUS G2 FTA as a Solution?); Rolf Weber (A New Trade Regime for Digital Assets); Jason Webb Yackee (Diplomacy as an Alternative to Law: Lessons from French Investment Disputes in PostColonial Africa in the 1960s/1970s); Weihuan Zhou (Theory of Distortions and Welfare as the Backbone of the WTO: If We Lose the Form, Do We Lose the Essence?).

${ }^{3}$ The workshops had academics from Australia, Austria, China, France, Germany, Hong Kong, India, Israel, Italy, Japan, Macau, Malaysia, Mexico, Portugal, Singapore, South Africa, South Korea, Switzerland, Taiwan, Turkey, United Kingdom, United States, and Uruguay. 
no one foresaw those eventualities and the significant consequences that would ensue from them. And so, the participants agreed that there is value in being prepared for a worst case or dystopian scenario for the WTO. Accordingly, it was felt that despite our commitments to multilateralism and specifically to a vibrant and dynamic WTO, it was nonetheless time that academics in our field began to seriously discuss what a post-WTO world could look like-both from utopian and dystopian perspectives. We thus could begin to contribute to what might be needed for the IELO in the future, or better yet, through these grim scenarios or idea of reform, actually help save the WTO and the commitment to a rule of law multilateralism for our fields.

Some papers can clearly be seen to have tackled the dystopian ${ }^{4}$ or utopian ${ }^{5}$ predictions, while others, reflecting the inevitable blurring of the ideas, straddle both utopian and dystopian perspectives. ${ }^{6}$ The current collection comprises but a fraction of all the presentations and papers due to the tight timeframe employed for this book to ensure that a publication was able to be disseminated quickly so as to play a role in the ongoing development of the field at this critical time in its life. It is hoped that the other works prepared for the project will appear individually or perhaps even as a second later volume covering these issues.

This introduction will lay out some of the general parameters and methodological approaches that are relevant for this sort of work, by the current chapters in this collection, the other presentations at the workshops (an earlier version of this paper was available to them), and most critically by future scholars and policy makers that will be confronting this reality-a WTO under intense pressure, a WTO that might not survive. There is no question that scholars and policy makers will be tackling these issues in the years to come, regardless of the resolution of the current crises at the WTO, and hence this chapter is intended to provide some scaffolding that could be employed for those later works.

\section{Project Conceptual Issues (e.g., Methodological and Theoretical Bases)}

This project, as well as the works to come addressing the possibilities in a post-WTO world are and will not necessarily be trying to predict the future-clearly an impossible task. ${ }^{7}$ Rather, what this project and related works are doing is to present possibilities of what a future for the international economic legal order (IELO) could

\footnotetext{
${ }^{4}$ See e.g. in this volume, Bradly Condon, To Dystopia and Beyond: The WTO in a Warming Megaregional World.

${ }^{5}$ See e.g. in this volume, Sonia Elise Roland and David Trubek, A Development-Driven Post-WTO World.

${ }^{6}$ See e.g. in this volume, Gabriel Gari, Narrowed Down Utopia: Adjusting the WTO to a Changing Trade Environment.

${ }^{7}$ Though, see Rescher (1998).
} 
look like when just one factor, albeit a large one, is taken out of the equation. In this case - what the future could look like if a healthy or robust WTO no longer existed.

The consequence of such a change could result in all sorts of possible futures, from dystopian to utopian IELOs, or perhaps that the overall status quo within the IELO is not in fact altered! Indeed, it can easily be imagined that a future without a "live" WTO might rather continue largely as now, maintaining the rough status quo. Such a scenario leads to the somewhat tongue-in-cheek question of "whether anyone would notice if the WTO ceased to exist". But, by the way we have positioned our project, namely by seeking utopian or dystopian consequences of the demise of the WTO, the project is searching to explore two opposites from this thought exercise (a thought exercise that is perhaps becoming ever more real each year). Both are somewhat extreme sets of scenarios, even as the project seeks to explore what might be the consequences of a WTO-less world.

Hence, this project's approach, varying one factor within the environment, and seeing what the consequences may be, is somewhat akin to counterfactual analyses. Though, it should be noted that counterfactual analyses are usually set in the past (e.g., what would have happened had Hitler's parents never met). But, unlike the complex methodological demands for well-presented counterfactuals, ${ }^{8}$ we have a relatively easy set of circumstances, namely, our timeline is sufficiently short and we can work with just one factor changed (the role or character of the WTO). We can also assume that the actors, principles and so on are largely consistent over the short time frame we are considering - say across the next 10 years. Nonetheless, scholars engaging in this sort of exercise might be well served to consider the many developed counterfactual methodological tools.

More directly, what of predicting the future? Clearly an impossible task, and yet in so many ways one which is repeatedly attempted-whether through academic exercises or through the machinations of forward-looking regulations and laws. But, for the explicit attempt, among the many approaches one could take three are briefly laid out below, though constrained to a 5-20 year time frame (otherwise it is too soon or too far off). ${ }^{9}$ The three approaches consist of:

1. Identification of the choices (the 'forks in the road') the field faces in the future;

2. Identification of the complex questions (not the binary questions reflected in the "forks" above) the field must answer in the future which will help to lay out the ground upon which the future will unfold; and

3. Identification of the forces and pressures (by states, corporations, etc.) that will help to determine the future of the field.

\footnotetext{
${ }^{8}$ See e.g. Tetlock and Belkin (1996), pp. 1-39.

${ }^{9}$ These approaches (including explaining why the timeframe should be between 5 and 20 years) are developed more fully in a draft article available at SSRN. See Picker CB (2020) Predicting the Future of International Trade Law. Available at SSRN: https://papers.ssrn.com/sol3/papers.cfm? abstract_id=3542889.
} 
Utilising these three approaches, and others ${ }^{10}$ can provide some rigour for such predictions in our field.

Of course, scholars investigating the consequences of a post-WTO world may draw on a wide range of methodologies and perspectives. Indeed, over the course of the three workshops a variety of those methodologies were utilised-though given that most legal research publications do not discuss their methodological approaches ${ }^{11}$ those approaches are more often not explicitly noted, and would need to be gleaned from the papers. Doctrinal approaches have been and would be the primary approach ${ }^{12}$ - given that approach dominates legal research, even though employed it typically remains unstated in most legal research publications. ${ }^{13}$

Comparative methodologies were also commonly employed, particularly via comparison with how other fields have weathered similar environments (e.g. how has investment survived and thrived (or not) with no overarching multilateral organization or agreed rules). ${ }^{14}$ Though, for those employing comparative methodologies, the usual pitfalls that should be avoided should be considered. ${ }^{15}$ Empirical methods appear to be unlikely to be employed in the sort of studies considered here given the forward nature of the exercise. Other methodologies as applied to this project find bases in, among others, socio-legal, ${ }^{16}$ technological, ${ }^{17}$ economic, ${ }^{18}$ and historical approaches. ${ }^{19}$

Of course, the methodological bases should not be (though too often are) confused with what might be the theoretical bases of the works. Though, we should note here that for purposes of this short introduction we will conflate theoretical bases of research with the perspectives brought to bear on the research or the paradigms laid over or around the research. We concede they are different from each other, but for the brief purposes presented here they are sufficiently akin to each other. Regardless, while the methodological approaches are typically less clearly presented in legal

\footnotetext{
${ }^{10}$ See e.g. the approach taken in this volume, Rostam J. Neuwirth, GAIA 2048-A 'Glocal Agency in Anthropocene': Cognitive and Institutional Change as 'Legal Science Fiction'.

${ }^{11}$ Picker (2013), pp. 21-48 (discussing potential reasons for death of discussions on methodological bases of research in IEL).

${ }^{12}$ While subject to different characterisations as to what is a doctrinal analysis, an example in this collection could be said to be that of Elisa Baroncini's work in Chap. 7. For an excellent explanation of what is and the role of doctrinal analysis in law, see Roux (2014), pp. 178 et seq.

${ }^{13}$ Shaffer (2008), p. 30. See also Trachtman (2008), p. 45.

${ }^{14}$ See e.g. in this volume, Jaemin Lee, What Can We Learn from Our Struggling Cousin? Recent Discussions on Reform of International Investment Law and Investment Dispute Settlement Proceedings.

${ }^{15}$ See e.g. Brand (2007), pp. 405-466; Reitz (1998), pp. 617-636.

${ }^{16}$ See e.g. in this volume, Leila Choukroune, The Concern with non-Concerns: For the End of Trade Dystopia, could be said to include socio-legal perspectives and approaches.

${ }^{17}$ See e.g. in this volume, Rolf Weber, A New International Trade Framework for Digital Assets.

${ }^{18}$ See e.g. in this volume, James Nedumpara and Akshaya Venkataraman, The Rise of Import Substitution Subsidies and Local Content Requirements in a Dystopian WTO 2.0 Regime.

${ }^{19}$ See e.g. in this volume, Simon Lester Waiting for Cordell Hull.
} 
research papers, the theoretical/perspective/paradigm bases are more often explicitly laid out or easily identified from their implicit centrality to the research output. Perhaps the more common theoretical/perspective/paradigms bases that will be present are liberal-economic, neoliberal, public choice theory, law and development, critical theoretical perspectives, feminist perspectives, and so on. ${ }^{20}$

\section{Approaches}

At a more tangible methodological level, the following are some of the potential approaches that were taken at the workshops and some that might be taken in future to tease out possible utopian and dystopian futures that result from the demise or stagnation of the WTO.

\subsection{Utopian}

To construct a utopian successor to the WTO there are, among other approaches, two fundamental directions that can be considered:

1. Identification of what might have been fundamentally negative aspects of the WTO and the environment that it propagated; and

2. Identification of the potential goals or objectives for any potential successor institution(s) to the WTO.

Each is considered in greater detail below.

\subsubsection{Fundamental Negative Features of the WTO}

Since even before it formally was launched there has been no shortage of criticisms of the WTO. The criticisms since have covered almost every aspect of the WTO. Perhaps most foundationally, is that some criticisms, most critically from some governments, have argued that there are fundamental, critical or fatal consequences within or around the WTO. In other words, and as described further below, those potential negative features of the WTO were a result of factors or characteristics belonging to or within the WTO (endogenous) or ones external or outside of the WTO (exogenous).

\footnotetext{
${ }^{20}$ Public choice theory is clearly a major part of the theoretical basis found in this volume, see e.g. in this volume, Brett Williams and Weihuan Zhou, If the WTO were to Break Down Completely, Would We Stoop and Build it up with Worn-Out Tools?.
} 
As one considers the failure of the WTO leading to the post-WTO, identifying any relevant causes that might have been endogenous could be helpful in constructing a utopian successor regime that should ideally better manage any internal problematic challenges or not then include those contributing fatal characteristics. Concededly, it may have been difficult to establish a consensus on what issues or features were or are still fundamentally negative within the WTO. Views vary in this respect depending on normative perspectives, individual interactions with the WTO and the IELO, the ideological background of the critic, the timeframe or period under consideration, and so on. Indeed, it may be that some features noted as negative by one WTO expert might be considered by other WTO experts as actually being one of the WTO's positive attributes. Adding complexity is that experts may differ on the degree of negativity and harm, with some believing a feature's harm is so fundamental that it may be directly responsible for the current potentially fatal crisis facing the WTO. Indeed, given the list of possible negative characteristics of the WTO any such lists could be quite lengthy.

The below includes a partial list of some of the outward facing endogenous factors that may have led or are in danger of leading to the demise or stagnation of the WTO:

- It was an organisation based on outdated approaches (e.g., a 1980s approach to multilateralism or an early 1990s commitment to the international rule of law);

- It did not respond to changed and changing circumstances (e.g., much of the technological advances are largely unmanaged by the WTO);

- Many individual states felt left out or disenfranchised (e.g., smaller economies in particular);

- Developing states felt the WTO Agreements and processes did not adequately support their interests (e.g., failure to advance agricultural liberalization);

- Many civil society groups felt their interests were not reflected (e.g., trade and the environment);

- One or two countries or regional blocks dominated to the detriment of the rest (e.g., the US and the EU in particular);

- Businesses and industry were inordinately influential (e.g., in the areas of intellectual property);

- Trade in agriculture was insufficiently a part of the regime (e.g., little advance beyond the Agreement on Agriculture);

- Preferential Trade agreements ("PTAs") displaced the WTO and/or undermined the WTO (e.g., the focus on bilateral and regional agreements even as the WTO never advanced);

- It failed to properly address the trade linkage debate and/or include related/ connected regimes (e.g. environmentalism, labour and human rights); and

- It did not address the uncompensated externalities of the IELO (e.g. environmental consequences);

No doubt the above list could be extended, but it is sufficient for this work and aspects of all of the above were found somewhere among many of the workshop 
presentations and in some of the works included in this volume, even as those presentations and the chapters provided additional examples or issues.

In addition, within the WTO Agreements, processes, culture and approaches there are potentially a whole host of very particular or specific issues and inward facing endogenous factors which may have had a disproportionate impact in producing some of the broad negative effects (and affects) on the WTO. Some might include:

- The "consensus rule" for "legislative" change or reform;

- The adherence to the "single undertaking" approach to negotiations;

- The "negative consensus" rule for adoption of DSB reports;

- Essentially no retrospective/retroactive compensation upon finalisation of disputes by the DSB;

- The many suggested failings of the $\mathrm{AB}$ and panels, which could provide a long list of its own here (see EU's recent reform proposal ${ }^{21}$ );

- Lack or insufficient compliance of "reporting requirements" by some members (e.g., subsidies); and

- Failure to enforce GATT Article XXIV sufficiently (and the weakness of the RTA committee);

However, what if one felt there were no negatives or few negatives of any significance? And that the demise of the WTO was due to exogenous factors that undermined the WTO. In fairness, it could be argued that any successor regime would also have these forces acting on it and so then we need to consider how to structure a utopian successor that would then be able to manage those exogenous factors. To do so we need to understand what those exogenous factors might have been or are likely to be so that a successor regime could then be developed to cope with them. Among many others, they could have been things like:

- The rise of populism and populist leaders (e.g. the U.S.'s President Donald Trump and the U.K.'s Prime Minister Boris Johnson);

- The rise of RTAs/PTAs/FTAs (e.g., the Comprehensive and Progressive Agreement for Trans-Pacific Partnership (CPTPP or TPP11) or the East Asian Regional Comprehensive Economic Partnership (RCEP));

- Unanticipated technology related trade issues (e.g., the role of data in the economy);

- Globalisation of supply chains;

- The rise of internet platformers (e.g., Google, Amazon and Facebook)

- Geopolitical changes (the rise of Russia, India and China since the birth of the WTO);

- Lingering poverty and uneven economic development;

- Population movements and demographic challenges;

\footnotetext{
${ }^{21}$ WTO, Communication from the European Union, China, Canada, India, Norway, New Zealand, Switzerland, Australia, Republic of Korea, Iceland, Singapore And Mexico to the General Council (26 November 2018) WT/GC/W/752. Available at http://trade.ec.europa.eu/doclib/docs/2018/ november/tradoc_157514.pdf.
} 
- Aggravated climate change;

- Ideological challenges to market-based economic theories; and

- The "Great Recession" or Global Financial Crisis.

The above list merely records the past exogenous factors—all of which are still relevant and which would need to be taken into account in any successor regime. Many of these factors were raised in some of the presentations and in some of the chapters in this volume, even as they raised other factors. And so, in addition, any successor regime would need to anticipate or be constructed with sufficient versatility and agility to handle the unanticipated exogenous forces that will arise in the future. Of course, predicting what those would be and how they would be managed is a difficult task.

Once these endogenous and exogenous factors have been identified, and a hierarchy assigned to them (necessarily identifying which were most critical/least critical), then one can begin to develop how a successor regime would have to manage these, with those most critical being most important to be rectified in any new regime(s). Of course, what is really behind this project is the idea that the insights and conclusions developed by considering a post-WTO could actually be brought to bear to help save the WTO - and so any developments supposedly for use by a successor regime could hopefully be employed to help save the WTO.

\subsubsection{Identify the Goals or Fundamental Character of the Successor Regime}

Identifying the goals or character of a successor utopian regime is necessary in order to know how to properly construct it and to consider how best to develop/nurture it in order to ensure its viability and sustainability. Of course, one could simply take the goals of the WTO as the goals for the successor regime, but what if those goals were fatally too limited or overly expansive and hence were themselves tied up in the failings of the WTO? Reassessing the successor regime(s) goals would thus be a useful exercise.

The goals or character of the regime can span a wide range, with diametrically opposed goals or characteristics possible. The below show some of these opposed goals/characters - some of which may have been thought to have been resolved with the birth of the WTO, but which are today subject to debate again. Of course, the below reflect the extremes, and the goals or approaches could take any point in between those listed approaches:

- A purely economic focus versus a holistic focus for the organisation (e.g. including environmental or human rights);

- Rule-of-Law or legalistic dispute resolution versus diplomatic resolution of disputes;

- Elevation of the global or multilateral interests at the expense of state or local interests; 
- A robust and dynamic legislative body versus strict retention of control by states for changes to the commitments;

- An institution of broad competence and coverage (e.g. including competition law, investment law, etc.) versus a narrow one or at the most minimal a simple treaty

Each of these and other goals formed part of the analyses of many of the presentations and in some of the chapters in this volume. The variety of goals proffered may itself be a major challenge for the current and any future regimes. Regardless, once the goals have been identified and ranked, if possible, then they too can be the basis by which aspects of a new regime could be constructed. And in keeping with the goal of saving the WTO, it might be relevant for reform of the WTO as well!

\subsection{Dystopian}

When considering a dystopian IELO following the demise or irrelevance of the WTO, among the many approaches that could be taken are the following three that get to the heart of the critical issues that should be considered:

1. Identification of those parts of the WTO that were successful and positive and hence likely absent in a dystopian future;

2. Identification of what might be the consequences if the positives delivered by the WTO were not replaced/substituted with approaches/regimes or devices that would have delivered an equivalent positive impact within the IELO; and

3. Identification of devices, institutions or approaches which might replace the WTO to deliver the equivalent role within the IELO.

\subsubsection{Successful or Positive Aspects of the WTO}

Again, like the above discussion of negative aspects of the WTO, determination of what was/is positive or successful in or by the WTO will likely be subject to considerable debate. There are differences of opinion once again varying with ideological, personal and experiential differences. Those differences were clearly visible in the different perspectives presented at the workshops and can also be found in the different perspectives found within this volume. ${ }^{22}$ Regardless, the below list could be viewed as endogenous positive or successful aspects of the WTO that would then either be absent in an imagined dystopian future or if possible should be reproduced/replaced by non-WTO means in a dystopian future that had no or an irrelevant WTO:

\footnotetext{
${ }^{22}$ E.g. compare in this volume, the works of Leila Choukroune, The Concern with non-Concerns: For the End of Trade Dystopia, with that of Simon Lester, Waiting for Cordell Hull.
} 
- Peaceful resolution of international trade disputes;

- Rule of Law governing international trade regulation;

- Development of trade law through jurisprudence;

- Sustaining multilateral approaches in the face of plurilateral challenges;

- Stopping increases in trade barriers;

- Reduction in trade barriers;

- Maintenance of lower or minimal trade barriers;

- Non-discrimination in tariffs and other trade measures; and

- Transparency in domestic trade regulations;

Once the positive characteristics or activities have been identified, and a hierarchy assigned to them (which would be the most critical/least critical), then one can begin to figure out how they could be replaced or reproduced, or their absence mitigated in a post-WTO IELO.

\subsubsection{Consequences of Not Replacing Those Positives}

While the best approach would be to reproduce or mitigate the lost positive attributes of the WTO, it is not unlikely that a successor regime to the WTO would struggle to do so. This is likely to be the case, at least in the short term, as many of the critiques and critics of the current regime, the WTO, would stand in the way of constructing a robust successor regime. As such, a post WTO IELO will likely not include those positive attributes or not include them to the same extent or reach. Even PTAs, the most likely forms of successor regimes to the WTO as noted in some of the works in this volume, ${ }^{23}$ while they may include the positive attributes, will only do so between the members of the PTA, and not even for them when they interact with states outside the PTA. Of course, it would also be absent for the IEL interactions between states who are not members of those PTAs.

Accordingly, when considering a dystopian IELO following the collapse or slide into irrelevance of the WTO each of the positive attributes lost would need to be examined in order to figure out the consequences for the IELO. It is likely that those consequences would be far reaching, not only within the IELO, but even intruding into local domestic economic orders. Indeed, there would possibly be knock-on effects into the non-IELO regimes including geopolitics, and so on. Of course, considering just the impact of the absence of one positive consequence of the WTO in the IELO (and within domestic economic orders) would be so complex that it alone would be sufficient to require a chapter or essay all of its own. Accordingly, researchers in the future could, if they wished, just pick one lost positive role of the WTO and examine the consequences to their logical, and perhaps even illogical or irrational, conclusions. I say illogical or irrational for when dealing with humans, governments and participants in economies we know that homo

\footnotetext{
${ }^{23}$ See e.g. in this volume, Engela Schlemmer, A Possible Hierarchy of Dispute Settlement Systems? and Peter-Tobias Stoll, Saving the World Trade Order from the Bottom Up: A Role for Preferential Trade Agreements.
} 
rationalis (homo economicus) is only present in unrealistic and sterile economic models.

Of course, perhaps not all is gloom and doom. While there would certainly be negative consequences of the loss of those positive WTO attributes, there may also be offsetting positives from the loss of the negative attributes of the WTO (see Part 3.1.1 above). So, while still a dystopian IELO, the issues raised by the loss of the WTO and its negative sides should also be studied, and would also be sufficiently complex and far reaching to deserve their own study. And as repeatedly noted above, the insights from such dystopian analyses may ultimately help to save the WTO by showing the dire consequences of letting the WTO expire or become irrelevant.

\subsection{Substitutes to Fill the Void Left by a Lost WTO}

The identification of devices, institutions or approaches which might replace the WTO to deliver the equivalent role within the IELO is clearly a critical component when considering how the IELO will survive or function in a post-WTO world. Some of the chapters in this collection have taken this approach, ${ }^{24}$ particularly through suggestions that international investment law should be looked at for possible models of a part of the IEL that has survived, perhaps even thrived, despite having a regime that is fragmented and mostly not multilateral. ${ }^{25}$

Another possibility to fill that void suggested in the collection focuses on the ability of the many different PTA regimes to both fill the substantive needs of the IELO (albeit on a non-multilateral basis) as well as stepping into the dispute resolution void that already exists given the current suspension of the WTO's AB to function. ${ }^{26}$

Future researchers may find that identifying substitutes to fulfil the roles of the WTO is the most critical and time sensitive part of the entire set of issues to be researched in a post-WTO world. After all, one should first ensure the IELO functions at a basic level, and then turn to restoring or building further the more sophisticated and progressive aspects of the IELO that is needed to ensure the most efficient and effective IELO.

Again, research and consideration of what might be replacements or substitutes for a lost WTO will actually help the WTO to survive its current challenges-for it becomes immediately clear that there are no easy or available substitutes to carry out the functions of the WTO, even as flawed or ineffective as one might have considered the WTO.

\footnotetext{
${ }^{24}$ See e.g. in this volume, Rolf Weber, A New International Trade Framework for Digital Assets.

${ }^{25}$ See e.g. in this volume, Chin Leng Lim, Reaching for Utopia, Geneva as Inspiration for Investment Disputes?.

${ }^{26}$ See e.g. in this volume, Tomohiko Kobayashi and Yuka Fukunaga, Like a Rolling Stone: Exploring Viable Options for the WTO Dispute Settlement Mechanism to Evolve Forward in the Post-WTO Era.
} 


\section{Conclusion}

The above are merely some potential approaches to what is a somewhat difficult and different exercise for many of the academics in our field. While these exercises may push some out of their comfort zone, forcing them to consider worst-case (and, if they desire, best-case) scenarios resulting from the loss or irrelevance of a beloved institution (the WTO, warts and all), it is nonetheless a vital task. After all, the many different ideas, reflecting imaginations unleashed, that were generated at the workshops, some of which are present in this collection and those works that will be inspired by this collection, will be useful not only if one were ever to look to models for a successor regime, but they could also suggest avenues for reform of the WTO-rescuing it from irrelevance or destruction. And perhaps even more critically, the dystopian examples would hopefully show the horrors that might arise if the WTO is allowed to fail, encouraging our policy makers to redouble their efforts to save the WTO.

\section{References}

Brand O (2007) Conceptual comparisons: towards a coherent methodology of comparative legal studies. Brook J Int Law 32(2):405-466

Picker CB (2013) Comparative legal cultural analyses of international economic law: a new methodological approach. Chin J Comp Law 1(1):21-48

Reitz CJ (1998) How to do comparative law. Am J Comp Law 46(1):617-636

Rescher N (1998) Predicting the future: an introduction to the theory of forecasting. State University of New York Press, Albany

Roux TR (2014) Judging the quality of legal research: a qualified response to the demand for greater methodological rigour. Leg Educ Rev 24(1):177-204

Shaffer G (2008) A new legal realism: method in international economic law scholarship. In: Picker $\mathrm{CB}$, Bunn ID, Arner D (eds) International economic law-the state and future of the discipline. Hart, Portland, pp 29-42

Tetlock PE, Belkin A (1996) Counterfactual thought experiments in world politics: logical, methodological and psychological perspectives. In: Tetlock PE, Belkin A (eds) Counterfactual thought experiments in world politics: logical, methodological and psychological perspectives. Princeton University Press, Princeton, pp 1-39

Trachtman JP (2008) International economic law research: a taxonomy. In: Picker CB, Bunn ID, Arner D (eds) International economic law-the state and future of the discipline. Hart, Portland, pp 43-52 